\title{
BMJ Open Coverage of common cancer types in UK national newspapers: a content analysis
}

\author{
Julie Konfortion, ${ }^{1,2}$ Ruth H Jack, ${ }^{1,2}$ Elizabeth A Davies ${ }^{1,2}$
}

To cite: Konfortion J, Jack RH, Davies EA. Coverage of common cancer types in UK national newspapers: a content analysis. BMJ Open 2014:4:e004677.

doi:10.1136/bmjopen-2013004677

- Prepublication history for this paper is available online. To view these files please visit the journal online (http://dx.doi.org/10.1136/ bmjopen-2013-004677).

Received 12 December 2013 Revised 19 June 2014 Accepted 20 June 2014

CrossMark

${ }^{1}$ Public Health England, Knowledge and Intelligence Team (London), London, UK ${ }^{2}$ King's College London, Cancer Epidemiology and Population Health, London, UK

Correspondence to Julie Konfortion; julie.konfortion@phe.gov.uk

\section{ABSTRACT}

Objective: To determine whether recent newspaper coverage of the four most common cancer types relates to their relative burden and national awareness months, and to identify the subject focus during highcoverage periods.

Design: Content analysis using the Nexis newspaper article database.

Setting: UK 2011-2012.

Outcome measures: Annual number and ranking, monthly proportions and subject of articles on breast, lung, bowel and prostate cancers.

Results: 9178 articles were identified during 2011 and 2012 featuring breast (4237), prostate (1757), lung (1746) and bowel (1438) cancer. Peaks in monthly proportions above the $99 \%$ upper confidence limit were identified for each. Breast cancer had the highest coverage of $12 \%$ and $17 \%$ during its awareness month. Smaller peaks (11\%) were identified during Bowel Cancer Awareness month. Prostate cancer received high coverage in relation to the case of the man convicted of the Lockerbie bombing who had been diagnosed with the cancer, and lung cancer in relation to the deaths of celebrities. Breast cancer was covered most often overall and by newspaper category while the lower coverage of other cancer types did not consistently mirror the relative number of new cases each year. The peaks by newspaper category were similar to the overall coverage with few exceptions.

Conclusions: UK newspaper coverage of common cancer types other than of the breast appears underrepresented relative to their population burden.

Coverage of breast cancer and bowel cancer appears to be influenced by their awareness months, while that of prostate cancer and lung cancer is influenced by other media stories. Health-promoting public bodies and campaigners could learn from the success of Breast Cancer Awareness Month and work more closely with journalists to ensure that the relevant messages reach wider audiences.

\section{INTRODUCTION}

Breast, lung, prostate and bowel cancer were the four most commonly diagnosed cancer types in the UK in 2010, which collectively accounted for over $50 \%$ of cancer

\section{Strengths and limitations of this study}

This study made novel use of an established comprehensive database and classification tool to identify the subject focus of newspaper articles. While this method allows a large number of articles to be assessed and to replicate and monitor the findings over time, a specific content analysis would reveal the more detailed messages and themes within them. National newspapers are a widespread form of media but others such as magazines, television, radio, online news and social media are not included and should be considered.

diagnoses. ${ }^{1}$ Each of these cancer types has associated awareness months which are increasingly used by charities and other nonprofit and public organisations to raise the profile of particular diseases, spread information about early symptoms or detection and raise funds for research or treatment. A leading example is Breast Cancer Awareness Month, which was introduced to the UK by the charity Breast Cancer Care in $1993 .{ }^{2}$ Bowel Cancer Awareness Month was established later in $2000,{ }^{3}$ followed by Lung Cancer Awareness Month in 2002 ${ }^{4}$ and Prostate Cancer Awareness Month in 2009. ${ }^{5}$

Given that most people do not meet medical professionals regularly, the media is a valuable means of raising public awareness and knowledge about cancer and disseminating health information in general. Studies carried out in China, the USA and the UK found that newspaper coverage generally did not mirror population cancer burden when measured as incidence, mortality or prevalence $^{6-8}$ This is not unexpected as the goals of mass media are generally information provision and entertainment. Journalists often need to deliver a story with 'human interest', which can mean that cancer news items may be biased towards personal accounts and risk distorting perceptions of the disease burden in populations. ${ }^{9}$ For example, stories about 
young female celebrities with cancer may create a false perception that the disease affects younger women more often than older women, such as the 'Kylie effect' resulting from the diagnosis of the Australian singer Kylie Minogue at age $36 .{ }^{10}$ The attention the UK media gave to the diagnosis of the celebrity Jade Goody with cervical cancer and her wish to raise awareness of screening led to a national debate about its effectiveness in young women, ${ }^{11}$ and an increase in screening coverage and information seeking. ${ }^{12}{ }^{13}$ Aside from celebrity stories, media campaigns have been shown to influence cancerrelated behaviours such as increasing cancer screening uptake in the USA and Australia, ${ }^{14-16}$ and reducing the use of sunbeds in Denmark. ${ }^{17}$

National newspapers are one widespread medium for cancer awareness but no study has yet evaluated whether awareness months affect cancer coverage in the UK. This study aimed to quantify recent national newspaper coverage of the four most commonly diagnosed cancer types, in particular to determine whether coverage was related to their relative population burden and whether national awareness months influenced the number of articles published in the UK. It also aimed to identify the subject focus of the articles published during awareness months or other high-coverage periods.

\section{METHODS}

Data were extracted from the well established, searchable news article database Nexis UK. ${ }^{18}$ The newspaper articles were identified by the keywords 'breast cancer', 'lung cancer', 'prostate cancer', 'bowel cancer', 'colorectal cancer', 'colon cancer' and 'rectal cancer'. The search was limited to newspaper articles published in 2011 and 2012 as the awareness month for prostate cancer had only started relatively recently, and the study intended to give the current picture of cancer coverage, forming the basis for future research. Articles were identified as those under the source category 'UK National Newspapers' and duplicates were eliminated. The national newspapers that the database included under this category were grouped into three categories, tabloid (Daily Star, Morning Star, The Mirror, The Sunday Mirror, The People and The Sun), middle-market (Daily

Table 1 Number of newly diagnosed cancer cases in the UK in 2010 and number of articles mentioning breast, lung, prostate and bowel cancers in UK national newspapers, 2011-2012

\begin{tabular}{|c|c|c|c|c|c|}
\hline \multirow[b]{2}{*}{ Cancer type } & \multicolumn{3}{|c|}{$\begin{array}{l}\text { Number of new cases } \\
\text { in } 2010^{1}\end{array}$} & \multicolumn{2}{|c|}{$\begin{array}{l}\text { Number of } \\
\text { articles (rank) }\end{array}$} \\
\hline & Persons & Males & Females & 2011 & 2012 \\
\hline Breast & 49961 & 397 & 49564 & 2102 (1) & 2135 (1) \\
\hline Lung & 42026 & 23175 & 18851 & $884(3)$ & $862(2)$ \\
\hline Prostate & 40975 & 40975 & - & $992(2)$ & 765 (3) \\
\hline Bowel & 40695 & 22834 & 17861 & 701 (4) & 737 (4) \\
\hline
\end{tabular}

Mail, The Mail on Sunday, The Express and The Sunday Express) and broadsheet (The Daily Telegraph, The Sunday Telegraph, The Guardian, The Observer, ie, The Independent, Independent on Sunday, The Times and The Sunday Times).

For each cancer type, the number of articles published in a month was divided by the number of articles published in that year. The mean number of articles was also calculated separately for the different newspaper categories, accounting for the difference in number of newspapers in each of the categories.

Peaks in coverage were identified as those above the 99\% upper confidence limit for the mean by cancer type and publication year. These were then matched to the cancer awareness months-March for prostate, April for bowel, October for breast and November for lung cancer. Population burden was measured as the number of newly diagnosed cases in 2010 - the year for which the most recent statistics were available.

The subject focus of each article was assigned by Nexis using the LexisNexis SmartIndexing Technology. This is a rule-based classification system developed by researchers and information professionals that is able to label articles with controlled vocabularies for the companies, industries, subjects, people and locations discussed within the documents. The system is regularly tested by Nexis and updated to ensure accuracy. In combination with source indexing, it is an easy and quick system to search for relevant articles by various sources or time periods. ${ }^{19}$ At the beginning of 2013, there were 19 main subject areas which were further divided into 191 more specific subjects and articles may have been tagged with more than one subject. The main subjects contributing to peaks in coverage above the $99 \%$ upper confidence limit were identified to give a general overview and articles were read to identify specific events which may have led to the rise. This analysis was repeated for tabloid, middle-market and broadsheet newspaper categories separately.

\section{RESULTS}

A total of 9178 articles relating to the four most commonly diagnosed cancer types in the UK were identified for the study period with a similar number published in each year. In both years, breast cancer and bowel cancer were consistently the most and least covered cancer types and this mirrored their ranking in terms of number of newly diagnosed cases (table 1). Generally, the five main subject areas for all articles about each of the cancer types were 'Medicine \& Health', 'Population \& Demographics', 'Science \& Technology', 'Society, Social Welfare \& Lifestyle' and 'Reports, Reviews \& Sections'.

\section{Overall coverage}

Coverage of breast cancer was the most frequent in both years with a total of 4237 articles. Peaks in its coverage 
A. Breast cancer
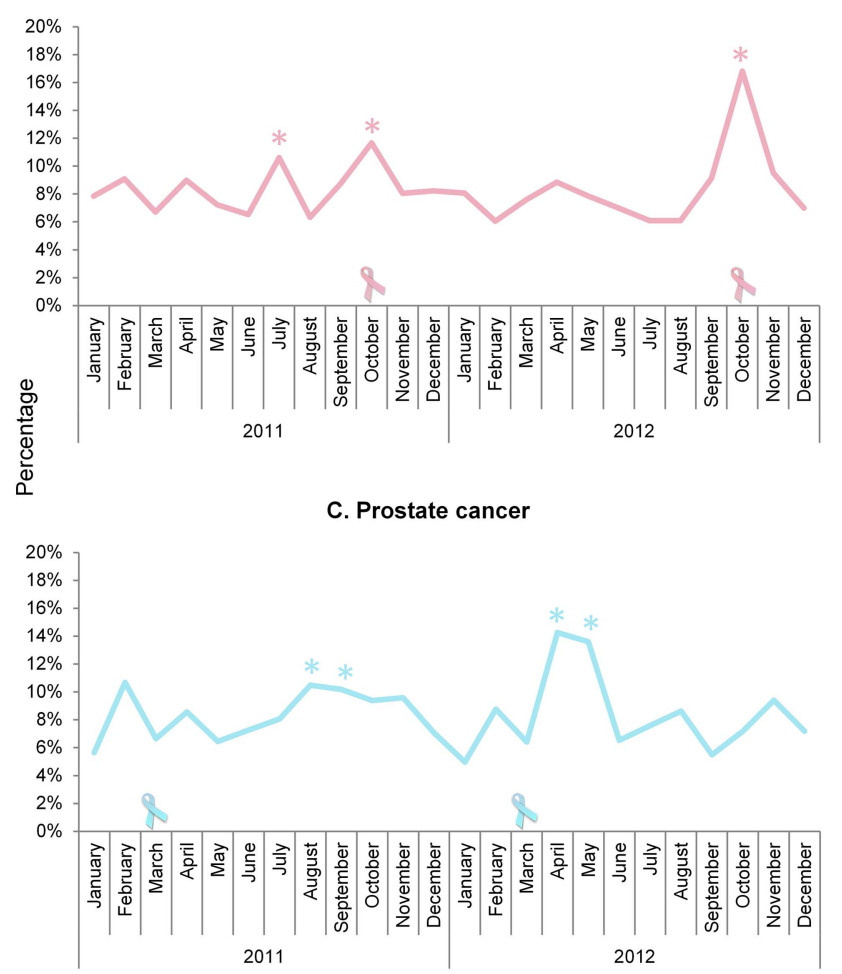

*Peaks above $99 \%$ upper confidence limit

Awareness month
B. Lung cancer

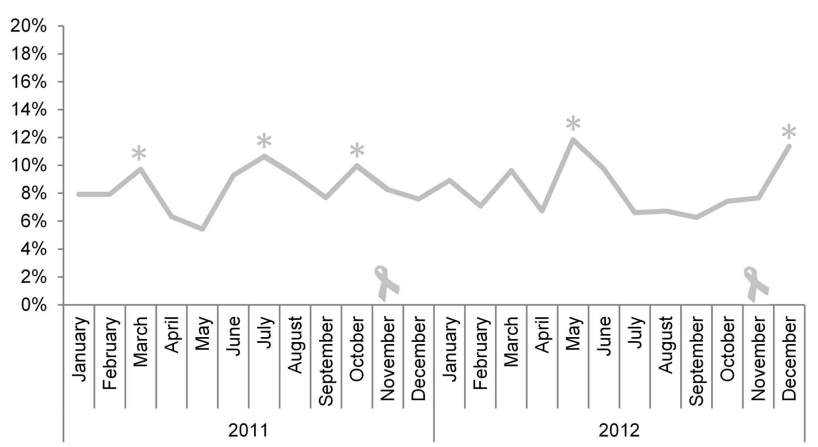

D. Bowel cancer

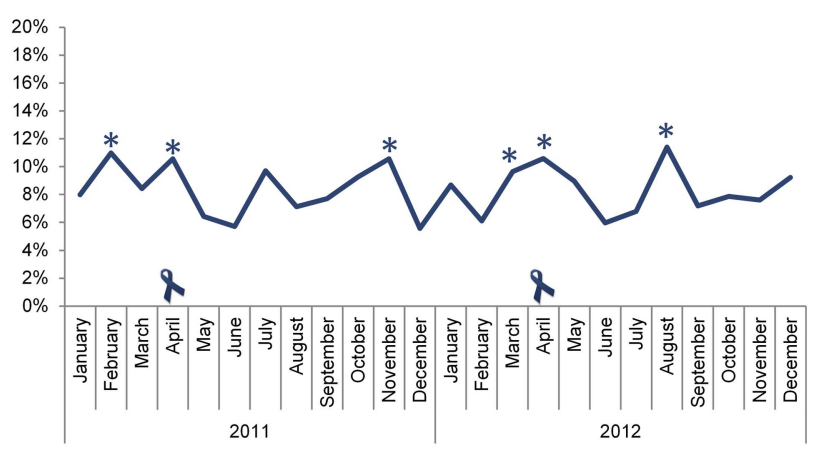

Figure 1 Proportion of breast, lung, prostate and bowel cancer articles published per month (in 2011 and 2012) in UK National newspapers overall.

were in July and October 2011, and October 2012 (figure 1A). Coverage in July 2011, which made up $11 \%$ of the published articles in that year, had a high proportion of articles tagged under the subject area 'Sports \& Recreation'. These articles referred to the case of a golf champion's wife who had died from breast cancer. October 2011 and 2012 had the highest proportions of coverage, $12 \%$ in 2011 and $17 \%$ in 2012, which coincided with Breast Cancer Awareness Month. The subject focus of these articles was still concentrated around the top five main subject areas.

Prostate cancer was the second most frequently mentioned cancer overall, being covered by 1757 articles. The proportions peaked in February, August and September 2011 at around 10\%, and in April and May 2012 at 14\% (figure 1C). These peaks all had a notable proportion of articles tagged under the subject area 'International Relations \& National Security' and these were mainly associated with the case of the man convicted of the Lockerbie bombing who had been diagnosed with prostate cancer. None of these peaks coincided with Prostate Cancer Awareness Month which takes place in March.

Lung cancer followed closely with 1746 articles over the 2 years. Peaks in the proportions of articles were identified in March, July and October 2011 at around 10\% (figure 1B). In 2012, peaks were observed in May and December at over
11\%. March 2011 saw a rise in articles relating to 'Government \& Public Administration', which were generally concerned with articles relating to compensation for victims of asbestos exposure. July 2011 saw a rise in articles that were confined to the top five main subject areas. There was also a rise in articles tagged under the subject area 'Humanities \& Social Sciences' for the months October 2011, May and December 2012; these were mainly covering stories about deaths from lung cancer, particularly of celebrities. There were no peaks in coverage observed during the cancer awareness month in November.

Bowel cancer was covered by 1438 newspaper articles during the study period. The peaks in proportions were observed in February, April and November 2011, each at around $10 \%$ (figure 1D). In 2012, the peaks were observed during March to April at around 10\% and in August at $11 \%$. All of the peaks consisted of articles assigned to the five main subject areas. There were peaks during Bowel Cancer Awareness Month in April 2011 and 2012 covering topics common to the rest of the year.

\section{Coverage by newspaper category}

When coverage was examined by newspaper category, breast cancer had the highest mean number of articles published over the 2-year period, 266 by tabloid, 265 by middle-market and 175 by broadsheet (table 2). The 
Table 2 Mean number of articles mentioning breast, lung, prostate and bowel cancers by newspaper category, 2011-2012

\begin{tabular}{lllcr}
\hline $\begin{array}{l}\text { Newspaper category } \\
\text { (number of }\end{array}$ & \multicolumn{4}{l}{ Cancer type } \\
\cline { 2 - 5 } newspapers) & Breast & Lung & Prostate & Bowel \\
\hline Broadsheet (9) & 175 & 88 & 83 & 55 \\
Middle-market (4) & 265 & 97 & 127 & 105 \\
Tabloid (6) & 266 & 94 & 83 & 87 \\
\hline
\end{tabular}

mean number of related articles was less than 130 for cancer types other than breast cancer in any category of newspaper.

A majority of the peaks observed by newspaper category were the same as the overall picture, or had no specific contributing event (figure 2A). The exceptions were for lung cancer peaks in broadsheet newspapers during June 2011 and March 2012 (figure 2B). The peak in June 2011 was related to the peace campaigner Brian Haw who died from lung cancer and was also observed in middle-market newspapers. March 2012 saw a rise in articles covering the success of a legal battle for compensation payments to sufferers of asbestos-related cancers. For prostate cancer, the only unique peak was observed for August 2012 in tabloid newspapers and was related to articles about the risks of eating fried meat and prostate cancer (figure 2C). Bowel cancer had a peak in middle-market newspapers for July 2011 which was related to the risk of death from side effects of capecitabine, a drug used to treat this cancer (figure 2D).

\section{DISCUSSION}

\section{Summary of main findings}

This study, using the Nexis newspaper database, found that UK national newspaper coverage of common cancer types did not always mirror the burden of newly diagnosed cases. During 2011, breast cancer and bowel cancer were the most and least commonly covered cancer types of those studied, but the coverage of lung and prostate cancer was not consistent with their burden. However, newspaper coverage in 2012 did mirror the ranking of newly diagnosed cases for all of the cancer types studied. Breast cancer was consistently the most commonly covered cancer by each of the tabloid, middle-market and broadsheet newspaper categories; although only in the latter group did the ranking of coverage mirror the relative disease burden. As well as breast cancer being highly reported throughout the 2-year study period, there were notable peaks coinciding with Breast Cancer Awareness Month in each October, both overall and by each newspaper category. The high proportion of breast cancer articles tagged under the most common subject areas of 'Medicine \& Health', 'Population \& Demographics', 'Science \& Technology', 'Society, Social Welfare \& Lifestyle' and
'Reports, Reviews \& Sections' during almost every month indicates that journalists and editors were generally prone to reporting articles under a limited number of subjects. However, there was high coverage of the case of a golf champion's wife who had died from breast cancer, supporting the idea that newspapers are responsive to reporting breast cancer in the context of personalisation. Considering the similar number of people diagnosed with prostate cancer each year, this cancer was under-represented in comparison with breast cancer. There was no rise in articles during its official awareness month in March. Instead, peaks in coverage were triggered by the case of the man convicted of the Lockerbie bombing who had been diagnosed with prostate cancer. Tabloid newspapers also had a peak in coverage of prostate cancer related to an increased risk caused by eating fried meat. In this case, tabloid newspapers were more likely to report on scientific research with a causation message compared with broadsheet and middle-market newspapers.

Peaks in articles relating to lung cancer were generally concerned with personal stories, such as asbestos exposure or cases of celebrities who had died from the disease. Bowel cancer articles covered a range of subjects with peaks triggered by events tagged under the five main subject areas. The exception was a peak in middlemarket newspapers' coverage, which had a small proportion of articles related to side effects of a bowel cancer drug. There were also peaks during its cancer awareness month in April in tabloid and broadsheet newspapers suggesting that journalists for these newspapers may have attempted to increase their coverage of bowel cancer during the campaign period.

\section{Comparison to other studies}

That breast cancer dominates media coverage in newspapers as well as magazines, television news broadcasts and online news is a consistent finding with previous research. ${ }^{6} 89{ }^{20-23}$ It has been suggested that this is likely to be due to the early establishment and effective marketing models used by breast cancer campaigners. ${ }^{7} 24$ Breast Cancer Awareness Month triggered heightened news coverage in this study and in the USA. ${ }^{25}$

Prostate cancer was one of the most frequent cancer types mentioned in previous studies of newspapers, magazines and online news. ${ }^{6} 2022$ Some also found that its coverage was under-represented, especially since the number of new diagnoses is similar to that of breast cancer. $^{9}{ }^{22}$ One reason for this may be that Prostate Cancer Awareness Month was introduced later than that for breast cancer. Another reason may be that the difficulty of screening for and identifying its early symptoms means that there is no national UK screening programme for newspapers to promote, unlike the widespread discussion in some other countries such as the $\mathrm{USA}^{26}$

Lung cancer was the second most commonly reported cancer in this study, consistent with other analyses of 
A. Breast cancer

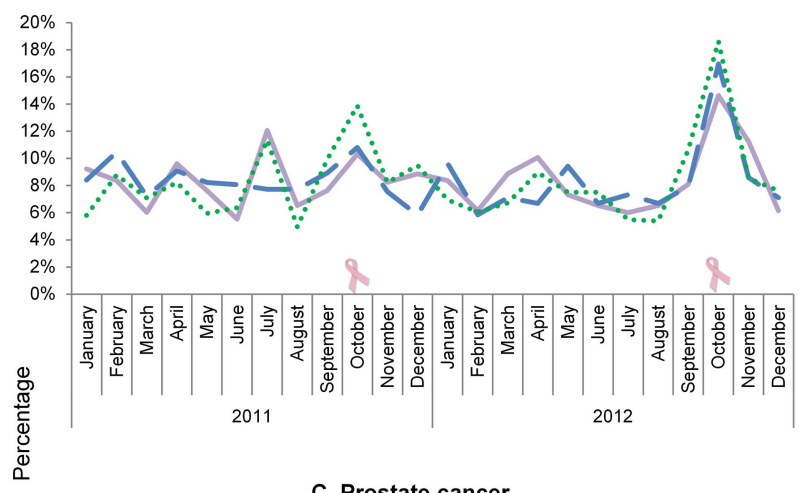

C. Prostate cancer

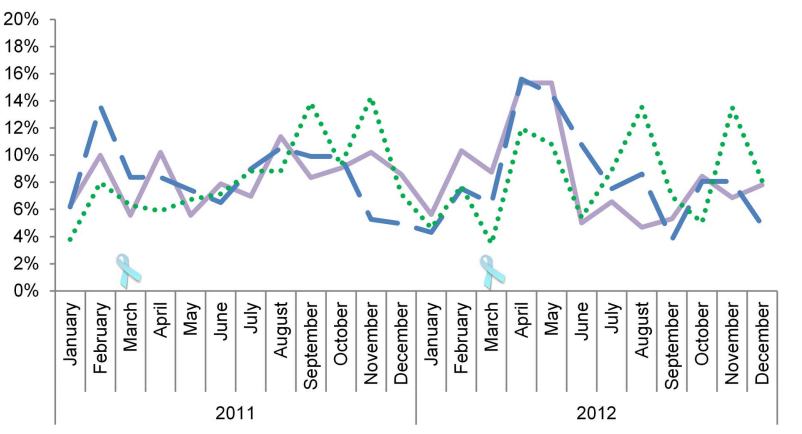

B. Lung cancer

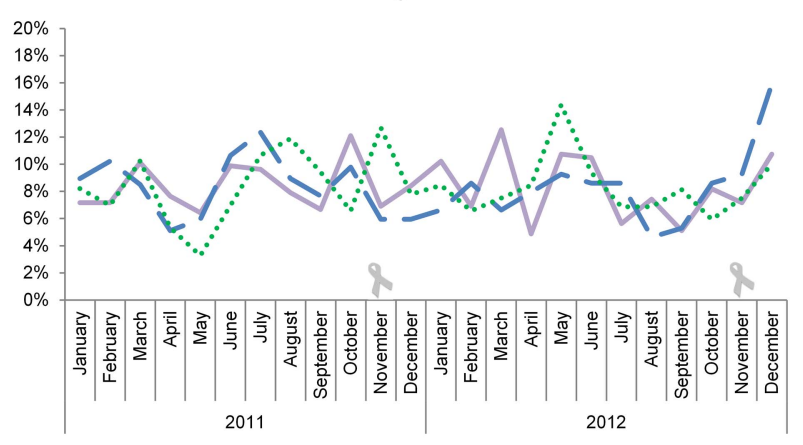

D. Bowel cancer

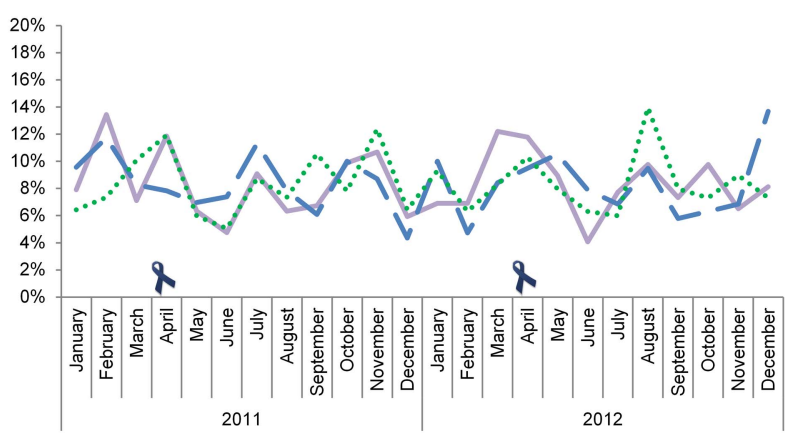

${ }^{*}$ Peaks above $99 \%$ upper confidence limit A Awareness month

— Broadsheet —-Middle-market ...... Tabloid

Figure 2 Proportion of breast, lung, prostate and bowel cancer articles published per month (in 2011 and 2012) by newspaper category.

newspaper coverage. ${ }^{6} 9$ Other studies have also found that this cancer was heavily under-represented, considering its high incidence and mortality rate. ${ }^{6-8}$ The exception was one of the Japanese newspapers that found lung cancer coverage to be the highest, consistent with mortality rates in Japan. ${ }^{27}$ This may be because Japanese newspapers covered a high proportion of death-related articles-a common subject for lung cancer articles in this study and in one US study. ${ }^{7}$

Bowel cancer was the least covered cancer type in this study. This study and others have found that media coverage of bowel cancer was generally underrepresented relative to its burden. ${ }^{6}{ }^{8} 21$ The peaks in newspaper coverage identified here in April, coinciding with Bowel Cancer Awareness Month, do, however, suggest an increasing success for this initiative. Similarly, a Swiss study found that a bowel cancer campaign led to increased newspaper coverage confined to the campaign period. $^{28}$ The other peaks identified in the current study consisted of articles relating to the common subject areas and were not related to any particular event. Another study carried out on UK national newspapers found that almost half of the newspaper articles mentioning bowel cancer were not actually relevant to the cancer. $^{29}$

The influence of celebrity cases on UK national newspaper coverage was observed in varying degrees across all of the cancer types studied, although some were of relatively low-profile cases compared with the wellstudied example of television celebrity Jade Goody whose experience with cervical cancer increased screening among British women. ${ }^{30} 31$ In the USA, cases of bowel cancer associated with high-profile figures has also led to a corresponding increase in the use of early detection tests. $^{32} 33$

\section{Strengths and potential limitations}

This study was unique in examining the influence of cancer awareness months on coverage in UK national newspapers. It was able to make use of existing classification tools to identify the focus of the articles retrieved, but this depends on the subjects already assigned rather than a new content analysis of the articles. The national newspapers included in this study, although comprehensive and representative, were part of a predefined category provided by Nexis and thus may be incomplete. However, the resource is well established and will allow for more consistent replication of the methods used in the future. This study only examined newspapers, which remain a popular and widespread source of information, although other media such as magazines, television broadcasts, radio, online news and social media are also important. In addition, the exploratory nature of this study meant that there was no examination of the content quality of the articles, but it can be argued that 
quantity will have a more powerful effect on public perceptions of disease.

\section{Implications for policy and practice}

Awareness months can only ever be one aspect of health promotion efforts to influence awareness of particular diseases, knowledge of when to act on particular symptoms, and individual behaviour change in response to them. Although there is some evidence that raising awareness of certain cancer types leads to earlier diagnosis or improved outcomes, this area of research still needs to be developed before effective interventions can be recommended. ${ }^{34}$ Under-representation of cancer types relative to their burden may, however, still impact on public knowledge and perceptions of risk, and on policies such as funding support. ${ }^{35}{ }^{36}$ While using personal experiences is an engaging method for profitmaking media, it is important that medical journalists ensure that accurate and relevant messages are presented in their articles whether in the context of a celebrity case or a specific awareness piece.

The marketing models employed by advocates during Breast Cancer Awareness Month have been successful at influencing the news coverage in US newspapers and subsequently affected health behaviours such as internet search activity. ${ }^{37}$ The increased UK newspaper coverage seen in this study for breast cancer and bowel cancer during their awareness months, but not for prostate and lung cancer, suggests that advocates should examine the methods used to promote breast and bowel cancer since evidence suggests that the media are responsive to such campaigning. ${ }^{9}$ Peaks of media coverage were also confined to campaign periods, and so a further challenge is to sustain relevant, accurate and appropriate messages to the public. Medical professionals, health-promoting public bodies and charities should collaborate more closely with medical journalists to ensure that relevant information is incorporated into articles, especially those reporting unpredictable news stories. Although the use of other media is increasing, newspapers may still be able to present the symptoms and treatment of some cancer types in an appealing manner which can make health promotion using other media difficult. For example, in one study, bowel cancer was more commonly covered by newspapers than magazines or television broadcasts compared with breast cancer. ${ }^{7}$ In addition, newspapers serve as a relatively low-cost route to reach a large, national audience. This study was unique in examining coverage by different categories of newspapers and found some minor distinction between the coverage of common cancer types. Different categories of newspapers attract audiences with similar characteristics and understanding this could help target and tailor messages to the at-risk groups. Health-promoting public bodies could also consider the use of extensive social media, which may also have a positive effect on health behaviours. ${ }^{17}$
Contributors JK, RHJ and EAD contributed to the study design. JK conducted data collection, and JK and RHJ the content analysis. JK and EAD drafted the manuscript. All authors contributed to the interpretation of results and commented on the manuscript.

Funding The work was carried out by the former Thames Cancer Registry in King's College London which received funding from the Department of Health. The study was completed with the support of the London Knowledge and Intelligence Team, Public Health England.

\section{Competing interests None.}

Provenance and peer review Not commissioned; externally peer reviewed.

Data sharing statement The data used for this study were accessed by authorised, non-transferable subscription to the Nexis database https://www. lexisnexis.com/uk/nexis/. Owing to the licensing agreements, interested parties will need to subscribe to this online service to retrieve data used in this study for similar research.

Open Access This is an Open Access article distributed in accordance with the Creative Commons Attribution Non Commercial (CC BY-NC 3.0) license, which permits others to distribute, remix, adapt, build upon this work noncommercially, and license their derivative works on different terms, provided the original work is properly cited and the use is non-commercial. See: http:// creativecommons.org/licenses/by-nc/3.0/

\section{REFERENCES}

1. Cancer Research UK. Cancer incidence in the UK in 20112014 [cited 13 Jun 2014]. http://publications.cancerresearchuk.org/ publicationformat/formatstats/incidence.html

2. Breast Cancer Care. Breast Cancer Awareness Month: why it's important 2012 [cited 20 Jun 2013]. http://www.breastcancercare. org.uk/news/blog/history-breast-cancer-awareness-month

3. Bowel Cancer UK. Bowel Cancer UK's History 2010 [cited 23 May 2014]. http://www.bowelcanceruk.org.uk/media/136171/historyfin.pdf

4. Lung Cancer Coalition. MPs unite to double lung cancer survival 2006 [cited 20 Jun 2013]. http://www.uklcc.org.uk/publications/ press-releases/63-mps-unite-to-double-lung-cancer-survival

5. UK Parliament. Early day motion 1045-Prostate Cancer Awareness Month 2008 [cited 19 Jun 2013]. http://www.parliament.uk/edm/ 2008-09/1045

6. Cai J, Yang L, Liu Z, et al. Comprehensive analysis of cancer coverage in important Chinese newspapers between 2000 and 2007. Support Care Cancer 2009;17:329-32.

7. Slater MD, Long M, Bettinghaus EP, et al. News coverage of cancer in the United States: a national sample of newspapers, television, and magazines. J Health Commun 2008;13:523-37.

8. Williamson JM, Jones IH, Hocken DB. How does the media profile of cancer compare with prevalence? Ann R Coll Surg Engl 2011;93:9-12.

9. Jensen JD, Moriarty CM, Hurley RJ, et al. Making sense of cancer news coverage trends: a comparison of three comprehensive content analyses. J Health Commun 2010;15:136-51.

10. Kelaher M, Cawson J, Miller J, et al. Use of breast cancer screening and treatment services by Australian women aged 25-44 years following Kylie Minogues breast cancer diagnosis. Int J Epidemiol 2008;37:1326-32.

11. Department of Health. Cervical cancer screening. http://www. publications.parliament.uk/pa/cm200809/cmhansrd/cm090313/ wmstext/90313m0001.htm2009

12. Metcalfe D, Price $C$, Powell J. Media coverage and public reaction to a celebrity cancer diagnosis. J Public Health (Oxf) 2011;33:80-5.

13. Lancucki L, Sasieni P, Patnick J, et al. The impact of Jade Goody's diagnosis and death on the NHS Cervical Screening Programme. J Med Screen 2012;19:89-93.

14. Anderson JO, Mullins RM, Siahpush M, et al. Mass media campaign improves cervical screening across all socio-economic groups. Health Educ Res 2009;24:867-75.

15. Schroy PC III, Glick JT, Robinson PA, et al. Has the surge in media attention increased public awareness about colorectal cancer and screening? J Community Health 2008;33:1-9.

16. Morrell S, Perez DA, Hardy M, et al. Outcomes from a mass media campaign to promote cervical screening in NSW, Australia. $J$ Epidemiol Community Health 2010;64:777-83.

17. Koster B, Thorgaard C, Philip A, et al. Sunbed use and campaign initiatives in the Danish population, 2007-2009: a cross-sectional study. J Eur Acad Dermatol Venereol 2011;25:1351-5. 
18. Nexis $₫$ [Internet]. 2013 [cited 23 May 2014]. http://www.lexisnexis. $\mathrm{com} / \mathrm{uk} / \mathrm{nexis}$

19. LexisNexis. Introduction to LexisNexis SmartIndexing Technology ${ }^{\mathrm{TM}}$ 2013 [cited 15 Oct 2013]. http://www.lexisnexis.com/infopro/ resource-centers/product_resource_centers/b/smartindexing/archive/ 2013/09/11/what-is-lexisnexis-smartindexing-technology.aspx

20. Clarke JN, Everest MM. Cancer in the mass print media: fear, uncertainty and the medical model. Soc Sci Med 2006;62: 2591-600.

21. Cohen EL, Caburnay CA, Luke DA, et al. Cancer coverage in general-audience and Black newspapers. Health Commun 2008;23:427-35

22. Henry M, Trickey B, Huang LN, et al. How is cancer recently portrayed in Canadian newspapers compared to 20 years ago? Support Care Cancer 2012;20:49-55.

23. Hurley RJ, Riles JM, Sangalang A. Online cancer news: trends regarding article types, specific cancers, and the cancer continuum. Health Commun 2014;29:41-50.

24. Harvey JA, Strahilevitz MA. The power of pink: cause-related marketing and the impact on breast cancer. JACR 2009;6: 26-32.

25. Cooper CP, Mallon KP, Leadbetter S, et al. Cancer Internet search activity on a major search engine, United States 2001-2003. JMIR 2005;7:36.

26. Smith KC, Kromm EE, Klassen AC. Print news coverage of cancer: what prevention messages are conveyed when screening is newsworthy? Cancer Epidemiol 2010;34:434-41.

27. Kishi $Y$, Nagamatsu S, Takita M, et al. Trends in cancer coverage in Japanese newspapers. J Clin Oncol 2008;26:6017-20.
28. Wang-Buholzer CF, Lomazzi M, Borisch B. Media response to colon cancer campaigns in Switzerland 2005-2007: regional newspapers are the most reliable among the printed media. BMC Res Notes 2010;3:177.

29. Jones IH, Williamson JM, Hocken DB. How informative is the print media coverage of colorectal cancer? Colorectal Dis 2012;14:250-2.

30. Walter T. Jade and the journalists: media coverage of a young British celebrity dying of cancer. Soc Sci Med 2010;71:853-60.

31. MacArthur GJ, Wright $\mathrm{M}, \mathrm{Beer} \mathrm{H}$, et al. Impact of media reporting of cervical cancer in a UK celebrity on a population-based cervical screening programme. J Med Screen 2011;18:204-9.

32. Cram P, Fendrick AM, Inadomi J, et al. The impact of a celebrity promotional campaign on the use of colon cancer screening: the Katie Couric effect. Arch Intern Med 2003;163:1601-5.

33. Brown ML, Potosky AL. The presidential effect: the public health response to media coverage about Ronald Reagan's colon cancer episode. Public Opin Q 1990;54:317-29.

34. Lyon D, Knowles J, Slater B, et al. Improving the early presentation of cancer symptoms in disadvantaged communities: putting local people in control. Br J Cancer 2009;101(Suppl 2):S49-54.

35. National Cancer Institute. Cancer Research Funding. 2013 http://www.cancer.gov/cancertopics/factsheet/NCl/research-funding (accessed 7 Jul 2014).

36. Robb K, Stubbings S, Ramirez A, et al. Public awareness of cancer in Britain: a population-based survey of adults. $\mathrm{Br} \mathrm{J}$ Cancer 2009;101(Suppl 2):S18-23.

37. Glynn RW, Kelly JC, Coffey N, et al. The effect of breast cancer awareness month on internet search activity-a comparison with awareness campaigns for lung and prostate cancer. BMC Cancer 2011;11:442. 